\title{
DISCIPLINA E PODER: BREVES CONSIDERAÇõES SOBRE A QUESTÃO DO CORPO NA FILOSOFIA DE MICHEL FOUCAULT ${ }^{1}$
}

\author{
Leandro Sousa Costa ${ }^{2}$ \\ Pontifícia Universidade Católica do Paraná (PUC/PR) \\ Universidade Estadual do Paraná (UNESPAR) \\ https://orcid.org/0000-0002-2427-3324 \\ E-mail: leandro_kallas@hotmail.com

\section{Leonardo Nunes Camargo ${ }^{3}$} \\ Pontifícia Universidade Católica do Paraná (PUC/PR) \\ https://orcid.org/0000-0002-3370-1327 \\ E-mail: leonardonncamargo@gmail.com
}

\section{RESUMO:}

Este artigo tem por finalidade apresentar alguns aspectos relacionados à questão do corpo na filosofia de Michel Foucault. Para isso, a nossa investigação se dará em dois momentos: no primeiro momento analisaremos a relação do corpo com a medicina para percebermos como a visão deste saber sobre o corpo se modificou a partir do século XVII, veremos que há uma relação entre o olhar médico e o corpo em si. O segundo momento será dedicado a uma explicitação acerca da relação entre poder e corpo; será possível notar que as práticas subjetivas são determinadas a partir de dispositivos culturais próprios de uma realidade cultural. No esteio disso, o poder disciplinar, que tem o seu ideal no panóptico, foi elemento preponderante para o projeto de domesticação dos corpos. Enfim, não é possível afirmar uma teoria sobre o corpo, no pensamento do filósofo francês, pois a sua investigação traz à tona a complexidade das estruturas culturais que determinam as diversas percepções a respeito desse corpo.

PALAVRAS-CHAVE: Corpo; Clínica; Michel Foucault; Medicina.

\section{DISCIPLINE AND POWER: BRIEF CONSIDERATIONS ON THE QUESTION OF THE BODY IN THE PHILOSOPHY OF MICHEL FOUCAULT}

\begin{abstract}
:
This article has aims to present some aspects related to the question of the body in the philosophy of Michel Foucault. For this, our investigation will happen in two moments: in the first moment we will analyze the relation of the body with medicine to perceive how the vision of this knowledge about the body has changed since the seventeenth century, we will see that there is a relation between the medical view and the body itself. The second moment will be dedicated to an explanation about the relation between power and body; it will be possible to notice that the subjective practices are determined from cultural devices proper to a cultural reality. In this respect, disciplinary power, which has its base in the panopticon, was preponderant element for the design of the domestication of bodies. Finally, it is not possible to affirm a theory about the body in the French philosopher's thought, because his investigation brings to light the complexity of the cultural structures that determine the diverse perceptions about this body.
\end{abstract}

KEYWORDS: Body; Clinic; Michel Foucault; Medicine.

\footnotetext{
${ }^{1}$ O presente trabalho foi realizado com apoio da Coordenação de Aperfeiçoamento de Pessoal de Nível Superior - Brasil (CAPES) - Código de Financiamento 001.

${ }^{2}$ Doutorando em Filosofia na Pontifícia Universidade Católica do Paraná (PUC/PR), Curitiba - PR, Brasil. Professor da Universidade Estadual do Paraná (UNESPAR), União da Vitória - PR, Brasil.

${ }^{3}$ Doutorando em Filosofia na Pontifícia Universidade Católica do Paraná (PUC/PR), Curitiba- PR, Brasil.
}

COSTA, Leandro Sousa; CAMARGO, Leonardo Nunes. Disciplina e poder: breves considerações sobre a questão do corpo na filosofia de Michel Foucault. Griot : Revista de Filosofia, Amargosa - BA, v.19, n.1, p.127-138, fevereiro, 2019. 


\section{O corpo na filosofia de Foucault}

Não há, na filosofia de Foucault, uma discussão que se proponha a desenvolver uma teoria sobre o corpo. Essa questão é interessante, pois, no contexto da história da filosofia ocidental, não encontramos uma sistematização de caráter exclusivista que tente dar conta de encerrar numa teoria o objeto em questão. Todavia, percebemos que, nos últimos tempos, a começar pela última década do século XX, o corpo tem ganhando espaço em diversas áreas do saber de modo que ele está se tornando o elemento ordenador de muitas questões. Vejamos, por exemplo, na educação física, representado pelas academias e programas de definição corporal, na indústria farmacológica, que produz uma série de medicamentos a fim de cuidar e melhorar os corpos, na medicina estética que remodela partes do corpo deixando-o (supostamente) mais belo e produzindo alterações anatômicas, fisiológicas e genéticas bastante significativas.

Essa procura - quase que desarrazoada - para melhorar o corpo, deixa evidente o modo como a sociedade europeia ocidental o tem percebido: ele é um objeto de manipulação. Essa perspectiva está associada ao desenvolvimento tecnológico, produzido pela narrativa da modernidade, e é a partir dessa percepção que o corpo passa a ser um objeto de controle da ciência, uma vez que ele é matéria. Contudo, é de importância capital ressaltar que o corpo não pode ser tomado desvinculado da atividade pensante. Fato é que, enquanto sujeito, o ser humano só pode existir através e por meio de um corpo, nesse sentido, a materialidade é algo indispensável para a sobrevivência dos próprios homens.

O postulado da filosofia cartesiana a respeito do ser humano que o divide em res cogitans (atividade pensante) e res extensa (corpo material) acentuou ainda mais a impossibilidade de identificar o corpo enquanto uma unidade, ou seja, a partir de um monismo psicofísico. Nos últimos três séculos, porém, alguns filósofos se enveredam em projetos no intuito de tentar superar essa divisão ou, quem sabe, repensá-la a partir de outras bases epistemológicas, entre eles Merleau-Ponty, Spinoza e Nietzsche.

Nesse contexto, a obra de Foucault - em sua totalidade - não apresenta uma teoria consistente sobre a noção de corpo, mas elementos que permitem pensar uma filosofia do corpo, isso se dá, a nosso ver, na medida em que ele se propõe a fazer uma história da verdade e da subjetividade. É por esse motivo que a nossa intenção não é a de sistematizar uma teoria a respeito do corpo, até porque a proposição de um artigo não daria conta de fazê-lo com suficiência, mas apresentar duas leituras sobre tal fenômeno, no sentido de identificar elementos que nos permitam pensar uma filosofia do corpo no pensamento foucaultiano. A primeira está relacionada às técnicas do saber médico na sua relação com o corpo, e a segunda às formas de poder e o corpo. Nesses dois momentos, perceberemos que, assim como o francês pensava, o corpo não era uma essência fixa, presa a uma identidade material já dada, o próprio corpo era um elemento que precisava ser pensado e construído a partir de uma história do próprio sujeito, portanto, há uma descoberta individual do ser humano, do seu próprio corpo. Sendo assim, é possível assegurar que, o humano explora suas possibilidades de existência a partir do seu corpo e é o próprio autor quem nos assegura isso.

COSTA, Leandro Sousa; CAMARGO, Leonardo Nunes. Disciplina e poder: breves considerações sobre a questão do corpo na filosofia de Michel Foucault. Griot : Revista de Filosofia, Amargosa - BA, v.19, n.1, p.127-138, fevereiro, 2019. 
Então, o corpo, na sua materialidade, na sua carne, seria como o produto de seus próprios fantasmas. Afinal, o corpo do dançarino não é justamente um corpo dilatado segundo um espaço que lhe é ao mesmo tempo interior e exterior? E os drogados também, e os possuídos; os possuídos, cujo corpo torna-se inferno; os estigmatizados, cujo corpo torna-se sofrimento, resgate e salvação [...] As crianças, afinal, levam muito tempo para saber que têm um corpo. Durante meses, durante mais de um ano, elas têm apenas um corpo disperso, membros, cavidades, orifícios, e tudo isto só se organiza, tudo isto literalmente toma corpo somente na imagem do espelho. De um modo mais estranho ainda, os gregos de Homero não tinham uma palavra para designar a unidade do corpo. Por paradoxal que seja, diante de Tróia, abaixo dos muros defendidos por Heitor e seus companheiros, não havia corpos, mas braços erguidos, peitos intrépidos, pernas ágeis, capacetes cintilantes em cima de cabeças: não havia corpo (FOUCAULT apud FONSECA, 2015, pp. 27-28).

\section{O corpo como entendimento médico a partir d'O nascimento da clínica}

Como mencionamos, nossa primeira análise se refere a relação entre a medicina e o corpo, nessa fase perceberemos que a própria medicina trabalhou o corpo sob diferentes perspectivas, para isso, conhecer a enfermidade era determinante para uma compreensão sobre ele.

A obra de 1963 de Foucault, $O$ nascimento da clínica, possui um caráter histórico e crítico a fim de determinar as condições que possibilitavam um conhecimento da experiência médica principalmente na Idade Moderna. $O$ nascimento da clínica analisa o momento em que a medicina se efetivava enquanto prática e ciência e dessa forma o filósofo aponta para uma perspectiva que indica a eficiência do saber médico na determinação das verdades do corpo, por isso temos uma nova maneira de olhar para a fisiologia corporal, um olhar intermediado pelos saberes da medicina.

O corpo humano constitui, por direito de natureza, o espaço de origem e repartição da doença: espaço cujas linhas, volumes, superfícies e caminhos são fixados, segundo uma geografia agora familiar, pelo atlas anatômico. Esta ordem do corpo sólido e visível é, entretanto, apenas uma das maneiras da medicina espacializar a doença (FOUCAULT, 2008, p. 1).

A relação entre o espaço de configuração da doença e sua localização no corpo humano, enquanto mal, foi descoberto recentemente na história médica. Isso acontece quando o médico passa a olhar diretamente para o corpo quando ele está acometido por uma patologia, ou seja, o médico dirige seu olhar diretamente para o organismo e passa a identificar precisamente onde a doença ataca o indivíduo doente. Esse olhar técnico está em condições de dominar não só a doença, mas também o sujeito, na medida em que o discurso médico explicita aquilo que o sujeito é.

O ser humano quando olha seu corpo o faz de acordo com suas crenças, padrões culturais e científicos, nesse sentido, a medicina se constitui como um fator importante na análise e investigação científica do corpo. A autoridade médica, com seus procedimentos para com o corpo de outrem, valida suas informações através de

COSTA, Leandro Sousa; CAMARGO, Leonardo Nunes. Disciplina e poder: breves considerações sobre a questão do corpo na filosofia de Michel Foucault. Griot : Revista de Filosofia, Amargosa - BA, v.19, n.1, p.127-138, fevereiro, 2019. 
normas técnicas que são determinadas a partir de uma perspectiva dada pela relação problema-diagnóstico, isto é, para qualquer situação anormal no funcionamento do aparato fisiológico há uma prescrição médica que indica meios para o restabelecimento da normalidade. Em certa medida, o médico afirma que o próprio sujeito não sabe exatamente o que sente, uma vez que o mesmo não possui um arcabouço técnico-científico para se expressar com exatidão. A visão do indivíduo sobre seu corpo deve se adequar a visão instrumentalista e determinista da ciência médica. Nesse sentido, o sujeito se reduz a um conjunto de números, de dados, que são usados pelos governos para fazer política e justificar ações que subtraem de todas as formas a possibilidade da vida humana de se realizar dignamente. Por exemplo, usa-se das taxas de aumento da expectativa de vida para justificar uma reforma previdenciária que aumentaria o tempo de contribuição e de permanência do sujeito no trabalho, uma reforma trabalhista que precarizaria as relações de trabalho no tocante a direitos, entre outros.

A obra de Foucault nos ajuda a pensar o corpo como possível interpretação do olhar, ou seja, um corpo se apresentará em diferentes perspectivas a depender do modo como é olhado e por parte de quem olha. Sendo assim, estamos de acordo com a perspectiva que afirma que "o corpo não tem um valor em si mesmo, mas um valor dependente do lugar que ele ocupa" (RODRIGUES, 2003, p. 112) e, por isso, ele se constitui em dependência de um território discursivo.

Nesse sentido, a possibilidade de olhares sobre o corpo constitui as relações de poder, a partir dessas relações de poder são produzidos os saberes, que trazem à tona as disciplinas, essas, por sua vez, tendem a exercer um controle sobre o corpo e, portanto, representam um tipo de poder sobre o corpo. Contudo, o controle sobre o corpo não é exclusividade da sociedade moderna, pelo contrário, desde as civilizações antigas se exercia um controle sobre os corpos como, por exemplo, no regime de escravidão, no regime servil, as punições impostas pelas religiões, entre tantas outras. A diferença para a modernidade é que agora o controle e o uso do poder sobre o corpo é regido pelo saber técnico-científico mecanicista que também é intermediado pelo uso dos discursos. É na modernidade que a categoria "sujeito" tem a sua gênese. O sujeito é o indivíduo que se constitui por práticas e os discursos técnicos tem a capacidade de não só determinar as práticas de sujeição, mas desvelar, por meio do discurso, quem é esse sujeito. E nesse caso, o saber médico assumiu essa função. Ora, o desenvolvimento do saber médico tornou-se tão poderoso que é ele quem vai nos dizer qual sujeito pode ser considerado criança, ou qual sujeito pode ser considerado morto ou vivo, ou adulto, ou louco, ou doente, ou sadio.

É na obra $O$ nascimento da clínica que poderemos perceber que o hospital torna-se "instrumento terapêutico de intervenção" (YAZBEK, 2014, p.98) sobre o corpo doente e a enfermidade, por isso, se faz necessário a presença sistemática e uma observação profunda do médico nos hospitais. Nesse sentido, podemos elencar algumas características importantes nessa nova relação médico-doença-paciente: $1^{\circ} \mathrm{o}$ hospital torna-se objeto empírico do conhecimento; $2^{\circ}$ volta-se o olhar para a funcionalidade do hospital, ou seja, quais são as possíveis relações entre os fenômenos patológicos e a distribuição nos pacientes; $3^{\circ}$ os médicos se tornaram os cientistas responsáveis pela investigação dentro do hospital; $4^{\circ}$ por fim, o hospital torna-se o local que realiza a cura, diferentemente de épocas anteriores que o mesmo

COSTA, Leandro Sousa; CAMARGO, Leonardo Nunes. Disciplina e poder: breves considerações sobre a questão do corpo na filosofia de Michel Foucault. Griot : Revista de Filosofia, Amargosa - BA, v.19, n.1, p.127-138, fevereiro, 2019. 
era visto apenas para receber pobres e dar assistência a eles. $E$ isso só foi possível pela reorganização estrutural, política e administrativa dos hospitais; tal fato teve a sua gênese e o seu desenvolvimento naquilo que, segundo a história europeia ocidental, chamamos de modernidade (séculos XVI a XVIII).

Queremos, a partir dos elementos que destacamos, identificar três momentos distintos na obra que mostram como a relação corpo e olhar médico se modificou na modernidade, a saber: a medicina classificatória, a medicina clínica e a medicina anatomopatológica. A medicina classificatória permite uma espécie de configuração da doença e por isso é possível perceber em quais situações um corpo não está em condições fisiológicas normais (Cf. FOUCAULT, 2008, p. 3). A doença passa a ser identificada em determinado instante, a medicina clássica do século XVII percebe a enfermidade dentro de uma situação no espaço nosológico, por isso, dizemos que a medicina se tornou um olhar classificatório, pois o médico passa a identificar as doenças dentro de um determinado campo de atuação através do olhar.

\begin{abstract}
A função capital da ciência médica será, justamente, a de neutralizar os elementos acidentais representados pelo médico e pelo doente [...], elementos contingenciais em relação a um conhecimento cuja tarefa consiste em fixar o lugar ideal da doença em ordem também ideal das espécies (YAZBEK, 2014, p. 58).
\end{abstract}

É por isso que, para a medicina clínica surgida no final do século XVIII, o ver e o dizer tornam-se elementos indispensáveis para a configuração do conhecimento médico, graças aos avanços em seus objetos, instrumentos, métodos e conceitos, e com a ampliação do saber médico emprega-se uma nova visão à doença. Todo o conjunto que constitui o que podemos chamar de identificação da doença mudou em sua totalidade, isto é, a doença e suas causas passaram a ser entendidas em suas diversas formas, isso acontece graças a novos códigos do saber. Na medicina clínica a doença se oferece inteiramente ao olhar, ao contrário, da medicina classificatória na qual o olhar servia para se conhecer a teoria, no caso da medicina clínica, o médico, ao mesmo tempo em que observa e é capaz de identificar a enfermidade, "funda seu objeto na sensorialidade do saber" (YAZBEK, 2014, p. 59).

Estabelece-se aqui, pois, uma relação entre percepção e linguagem propriamente médica, a verdade sobre a doença passa a se manifestar diretamente no corpo, só se pode dizer algo sobre a doença no campo do empírico com um campo enunciativo específico. Na medicina clínica, o olhar médico e a doença em si não possuem uma mediação, uma determinada enfermidade passa a ser vista de forma integral. Temos uma mudança na relação doença/signo/sintoma, ou seja, a doença passa a se revelar em sua condição sensível, o sintoma torna-se signo da própria doença, de modo que agora é possível observar os sintomas claramente no corpo sensível. De acordo com Foucault, "o sintoma se torna, portanto, signo sob um olhar sensível à diferença, à simultaneidade ou à sucessão, e à frequência" (FOUCAULT, 2008, p. 102).

Por fim, nesse primeiro momento, queremos analisar a medicina anatomoclínica. Tal medicina do século XIX representa a relação entre prática clínica e anatomia patológica e, desse modo, Foucault pretende explicitar que o corpo enquanto espaço tangível, que ocupa uma massa, que possui lesões, cheio de

COSTA, Leandro Sousa; CAMARGO, Leonardo Nunes. Disciplina e poder: breves considerações sobre a questão do corpo na filosofia de Michel Foucault. Griot : Revista de Filosofia, Amargosa - BA, v.19, n.1, p.127-138, fevereiro, 2019. 
incógnitas é passível de uma análise materialista. Tal medicina ultrapassa o olhar médico dos séculos anteriores que observavam apenas a superfície do corpo, na anatomoclínica procura-se identificar as camadas mais profundas do corpo humano, nasce um conjunto de técnicas que permitem ao médico construir um corpo a partir da anatomia, nessa fase a autópsia é essencial para se conhecer e estudar o corpo. Identificar uma enfermidade já não é suficiente, é preciso identificá-la em determinado órgão, localizar precisamente a região afetada é dessa maneira que se pode criar um discurso adequado para dar conta de falar sobre determinada patologia e de curá-la.

Nesse momento da medicina o corpo torna-se o elemento central da análise médica. $\mathrm{O}$ corpo torna-se doente. Se nas medicinas anteriores a linguagem possuía alguma supremacia sobre o olhar, nessa nova medicina olhar o corpo doente é mais necessário que a linguagem nosográfica. Podemos dizer que com o nascimento da medicina anatomoclínica constitui-se um novo saber sobre o sujeito, no sentido de que analisar um corpo, ou seja, fazer uma autópsia, configura a análise de um corpo particular, uma vez que a autópsia detecta com maior precisão o lugar em que a doença acometeu o corpo em questão e o levou à morte. Sendo assim, a própria morte precisou ser incorporada ao saber médico, para que a doença passasse a ser vista no corpo do indivíduo. É por isso que, a título de finalização da discussão dessa seção, Foucault nos assegura que "linguagem e morte atuaram, em cada nível desta experiência e segundo toda sua espessura, para finalmente oferecer a uma percepção científica o que durante muito tempo tinha permanecido como o invisível visível proibição e iminente segredo: o saber sobre o indivíduo" (FOUCAULT, 2008, p. 188189).

\section{As relações de poder e o corpo: os saberes e as práticas sociais do sujeito}

Neste momento passamos a analisar a segunda possível interpretação do corpo e sua relação com o poder na obra de Foucault. Sobre o poder precisamos mencionar sua relação com o saber, isto é, o autor quer evidenciar como os saberes transformavam e constituíam as práticas sociais de determinado povo. Para investigar a história, segundo o filósofo francês, precisamos entendê-la não como um processo contínuo, rumo ao progresso, mas a partir de épocas independentes e descontínuas. Essas épocas históricas são conhecidas como epistemes. Uma episteme age de forma inconsciente e é capaz de determinar a formação dos discursos e das práticas discursivas de uma sociedade dentro daquele período cultural. De acordo com Foucault a episteme é:

Onde os conhecimentos, encarados fora de qualquer critério referente a seu valor racional ou a suas formas objetivas, enraízam sua positividade e manifestam assim uma história que não é a de sua perfeição crescente, mas, antes, a de suas condições de possibilidade; nesse relato, o que deve aparecer são, no espaço do saber, as configurações que deram lugar às formas diversas do conhecimento empírico (FOUCAULT, 1981.p. 11-12).

A função da episteme é, portanto, determinar no campo do saber os discursos que serão considerados verdadeiros tanto pelos cientistas como pelas demais pessoas

COSTA, Leandro Sousa; CAMARGO, Leonardo Nunes. Disciplina e poder: breves considerações sobre a questão do corpo na filosofia de Michel Foucault. Griot : Revista de Filosofia, Amargosa - BA, v.19, n.1, p.127-138, fevereiro, 2019. 
da sociedade. Por buscar as causas que formam uma episteme e que servem de sustentação para aquela sociedade é que estamos no período da arqueologia na filosofia de Foucault. Por isso, o saber será determinante nessa fase, pois ele "forma um conjunto de regras que definem os objetos possíveis, a posição do sujeito em relação aos objetos, os conceitos que podem se constituir e os problemas que podem surgir" (RODRIGUES, 2003, p. 114). Nessa ótica, as verdades são dependentes desses movimentos da cultura que caracterizam a episteme de um período e, sendo assim, continua Rodrigues, "o saber, juntamente com suas práticas discursivas, delimita toda a possível realidade social" (RODRIGUES, 2003, p. 114).

A partir dessa constituição do saber, Foucault passa a analisar o poder. Para ele, os discursos de saber proferidos tem como função determinar o poder de uma verdade e também estabelecer quais saberes devem continuar existindo e quais devem ser extintos daquela sociedade. Dessa forma, o próprio discurso gera saber e poder.

Com isso, os acontecimentos históricos, para Foucault, são momentos aleatórios, contingentes, determinados pelo acaso e não por uma racionalidade. Mas o que nos interessa aqui é a análise que Foucault faz do modo como as relações de poder interferem na vida cotidiana das pessoas. Nesse sentido, o autor analisa o poder como uma espécie de micropoderes que agem em todos os indivíduos de maneira repetitiva nas diversas práticas realizadas ao longo do dia. Essas práticas, ao se repetirem cotidianamente, adestram os corpos, esse poder não parte de um governo central, pelo contrário, ele se dá na realidade concreta das pessoas, no ordinário do cotidiano, de forma até mesmo imperceptível. Assim, nossos corpos são constantemente modelados e controlados por esses micropoderes.

\begin{abstract}
As relações de poder existem entre um homem e uma mulher, entre aquele que sabe e aquele que não sabe, entre os pais e as crianças, na família. Na sociedade, há milhares e milhares de relações de poder e, por conseguinte, relações de forças de pequenos enfrentamentos, micro lutas de algum modo. Se é verdade que estas pequenas relações de poder são com freqüência comandadas, induzidas do alto pelos grandes poderes de Estado ou pelas grandes dominações de classe, é preciso ainda dizer que, em sentido inverso, uma dominação de classe ou uma estrutura de Estado só podem bem funcionar se há, na base, essas pequenas relações de poder. $O$ que seria o poder de Estado, aquele que impõe, por exemplo, o serviço militar, se não houvesse em torno de cada indivíduo todo um feixe de relações de poder que o liga a seus pais, a seu patrão, a seu professor àquele que sabe, àquele que lhe enfiou na cabeça tal e tal idéia? (FOUCAULT, 2003, p. 231).
\end{abstract}

Em Vigiar e punir, Foucault faz uma explicitação dos sistemas penitenciários como um local no qual ocorre de maneira clara a disciplinarização dos corpos, evidentemente devemos lembrar que tal disciplinarização também ocorre nas escolas, nas fábricas, nos hospitais, nas igrejas, entre outros. Pela disciplinarização os sujeitos são coagidos a se estabelecem a partir de práticas específicas. Tais práticas são reguladas por discursos que comandam as atividades desses sujeitos. A perspectiva dessa questão gira em torno da ideia de punição, por isso, temos a punição como uma função social, além da ideia de repressão; temos também a punição como um

COSTA, Leandro Sousa; CAMARGO, Leonardo Nunes. Disciplina e poder: breves considerações sobre a questão do corpo na filosofia de Michel Foucault. Griot : Revista de Filosofia, Amargosa - BA, v.19, n.1, p.127-138, fevereiro, 2019. 
procedimento de poder a disposição da política, dessa forma "o corpo passou a ser sujeitado a espaços e técnicas disciplinares que permitiram "dar nascimento" ao homem como objeto de saber para um discurso com estatuto científico" (SILVA, 2008, pp. 91-92). A partir disso, temos das relações de poder, os mecanismos de coação, disciplina ee controle dos sujeitos, surge algo que constantemente reivindica a resistência, ou seja, as ideias de luta constante contra as formas de poder que estão assumidamente presentes na sociedade. Contudo, o objetivo da prisão a partir do século XIX deixou de ser apenas punitivo e se tornou também um local para educar e formar o corpo através de práticas disciplinares.

Graças aos dispositivos e técnicas de fabricação o sujeito passa a ser determinado na sociedade, temos assim um sujeito que realiza atividades de acordo com suas capacidades, bem como com as instruções sociais e políticas de uma sociedade. O que Foucault pretende é explicitar, a partir de uma releitura da história, como o sujeito se constitui através das relações de poder e saber. Nesse sentido, temos a percepção de que isso permite ao filósofo apontar para a tese de que o sujeito é uma constituição de caráter não só fisiológico, mas, fundamentalmente, político-discursivo. Dessa forma, de acordo com Foucault, não podemos pensar o ser humano como uma entidade que independe de suas práticas sociais estabelecidas pelas e nas relações de poder. Por meio de uma série de discursos sobre o saber, produzidos ao longo da história e através dos processos de subjetivação, o homem fabrica mecanismos de poder sobre os indivíduos, mecanismos estes que visam à regulação, o controle e a normalização sobre os corpos.

É válido destacar que, para Foucault, o poder não é algo estático, presente apenas no estado, mas são práticas e mecanismos presentes na sociedade que favorecem a construção de certos discursos que visam o controle e a disciplinarização de corpos, portanto de sujeitos. Com isso, os processos disciplinares se tornaram formas eficientes de dominação dos corpos nos meios sociais a partir de meados do século XVIII. Os fatores que ditam esses processos disciplinares estão ligados à economia, à política, ao âmbito científico, jurídico, religioso, médico, etc. Por isso, o corpo humano torna-se objeto de manipulação disciplinar, que tem como finalidade a sua domesticação, ou, em termos foucaultianos, torná-lo dócil.

\footnotetext{
O corpo humano entra numa maquinaria que o esquadrinha, o desarticula e o recompõe. Uma anatomia política', que é também igualmente uma 'mecânica do poder', está nascendo; ela define como se pode ter domínio sobre o corpo dos outros, não simplesmente para que façam o que se quer, mas que operem como se quer, com as técnicas, segundo a rapidez e a eficácia que se determina. A disciplina fabrica assim corpos submissos e exercitados, corpos 'dóceis'. A disciplina aumenta as forças do corpo (em termos econômicos de utilidade) e diminui essas mesmas forças (em termos políticos de obediência) (FOUCALT, 2000, p. 119).
}

Sendo assim, Foucault analisa as formas de poder que afetam e constituem o corpo. $\mathrm{O}$ autor quer identificar, pois, como os processos de produção de sentido e de construção da subjetividade atuam sobre o corpo; diante disso, vemos que tais processos não estão presentes no corpo em si, mas são operações que afetam o corpo. O corpo na proposta de Foucault é o local onde as técnicas de poder incidem, nesse sentido, o poder é extrínseco ao corpo. E não é apenas o poder que mantém relação

COSTA, Leandro Sousa; CAMARGO, Leonardo Nunes. Disciplina e poder: breves considerações sobre a questão do corpo na filosofia de Michel Foucault. Griot : Revista de Filosofia, Amargosa - BA, v.19, n.1, p.127-138, fevereiro, 2019. 
com o corpo, o próprio saber e o desejo de controle sobre os corpos se constitui numa espécie de tecnologia política do corpo.

O corpo, na filosofia foucaultiana, não pode ser dissociado do contexto no qual está inserido, pensar o corpo a partir das relações de saber e poder é uma forma de explicitar a realidade do corpo como um produto de técnicas. Nesse sentido, "as facetas do corpo são tornadas possíveis pelas proposições que acerca dele o saber explicita, assim como o modo de ser do corpo, seu funcionamento no tempo e espaço resulta de uma educação efetuada por técnicas de poder" (FONSECA, 2015, p. 22). Novamente temos o corpo como resultado de um processo e ponto de encontro entre os discursos de saber e poder.

\section{O poder disciplinar e o panóptico: uma relação com o corpo}

Chegamos à última fase de nossa investigação e aqui nos propormos a analisar como o poder disciplinar e o conceito de panóptico interfere e influencia os corpos dos indivíduos. De certa forma, iniciamos essa discussão no subitem anterior, e a nossa abordagem vai no sentido de complementá-la. Lembrando que uma das investigações feitas por Foucault em Vigiar e Punir se dirigia a forma como os sistemas prisionais tratavam os detentos, nesse aspecto o trabalho do filósofo centrou seus esforços numa análise do comportamento desses nas prisões. As prisões representam um dispositivo disciplinar que o estado tem à disposição para corrigir certos comportamentos indesejáveis de certos indivíduos e assim reinseri-los na sociedade. As técnicas de poder disciplinar têm, então, como estopim a gestão dos homens, isto é, através delas o sujeito torna-se mais útil para realizar seus trabalhos e atividades.

A disciplina é justamente o conjunto de técnicas de poder que tem como objetivo atingir o sujeito em sua singularidade. Uma das funções dos dispositivos disciplinares se refere a ideia de vigilância, ou seja, ao invés da punição e do castigo físico como forma de mostrar o poder, a vigilância se apresenta como um saber racional e normativo que regula - da forma mais eficiente - os corpos dos indivíduos. Evidentemente a vigilância não se aplica apenas ao sistema carcerário, pelo contrário, ela está presente em todas formas sociais. A sociedade torna-se disciplinada quando ela passa a reivindicar o poder controlador como algo desejável, isto é, a vigilância torna-se algo benéfico e que causa segurança e tranquilidade.

Essa disciplinarização do poder torna os indivíduos de determinada sociedade corpos dóceis, isto é, submetidos ao poder. A vigilância como poder disciplinar baseada no panoptismo, permite classificar e punir certos comportamentos. Graças ao emprego da ciência nos sistemas penais, os corpos passam a ser vigiados por meio de um sistema normativo, ou seja, vigiar significa incluir e normatizar. $\mathrm{O}$ modelo carcerário do panóptico constitui-se, na explicitação foucaultiana, no sistema ideal de domesticação de corpos.

Sobre o panoptismo é preciso dizer que se trata de um dispositivo no qual o olhar (vigiar) tem uma função determinante, isto é, trata-se de um modo no qual o ver induz a efeitos de poder. Esse modelo, de certa forma, substitui a ideia de corpo supliciado presente até o século XVII pela ideia de corpo disciplinado. A inversão que ocorre após o século XVIII começa a aplicar técnicas de controle

COSTA, Leandro Sousa; CAMARGO, Leonardo Nunes. Disciplina e poder: breves considerações sobre a questão do corpo na filosofia de Michel Foucault. Griot : Revista de Filosofia, Amargosa - BA, v.19, n.1, p.127-138, fevereiro, 2019. 
comportamental-político sobre o corpo, ou seja, ao invés de castigar os corpos e expô-los em praças públicas, criou-se regras, táticas e modelos de prisões que age de forma mais controladora por parte dos governos e interessados. A punição que era vista como um desejo do rei ou do soberano desloca-se a fim de defender a sociedade. Nesse período acontece a reforma do Direito Penal.

De acordo com Foucault, somos as engrenagens que movimentam a máquina panóptica, pois são as pessoas que alimentam os efeitos de poder. Aqui a vigilância desempenha sua total função, uma vez que, seu papel é distribuir e controlar as pessoas de toda a sociedade. Nesse sentido, o panóptico é uma técnica política que se estabelece como o exercício do poder disciplinar sobre outro indivíduo.

As tecnologias do poder (como o panoptismo) têm a função de produzir corpos dóceis, baseadas em práticas e saberes que visam tal produção. Mas será que essa produção de corpos dóceis ocorre apenas nos sistemas prisionais? Será que podemos estendê-los às fábricas, hospitais, escolas, igrejas, asilos, quartéis, academias, etc.? A vigilância exercida pelos profissionais dessas demais áreas da sociedade produz aquilo que Foucault chama de adestramento.

Aprender a comportar-se, movimentar-se, ser preciso e ter ritmo. Gestos são fabricados, e sentimentos são produzidos. Este adestramento é resultado da aplicação de técnicas positivas de sujeição baseadas em saberes pedagógicos, médicos, sociológicos, físicos etc. O corpo torna-se útil e eficiente, mas ao mesmo tempo torna-se dócil e submisso: o corpo só se torna força útil se é ao mesmo tempo corpo produtivo e corpo submisso (FOUCAULT apud RODRIGUES, 2003, p. 118).

Precisamos lembrar que para Foucault o poder disciplinar não possui apenas uma função negativa, isto é, o poder não tem apenas a função de punir e reprimir, mas tem a capacidade de despertar o desejo e o nível do saber nas pessoas. Nesse sentido, o poder não impede o saber, mas o seu contrário, ele produz saber, ou seja, só foi possível estabelecer um poder sobre o corpo a partir do momento que este corpo passou a ser conhecido e estudado. Dessa forma, temos um poder que produz também conhecimento e verdade.

\section{Considerações finais}

A fim de lançar algumas perspectivas sobre este trabalho, passemos às considerações finais. Podemos dizer que, em Foucault, não é possível ter uma visão única e completa sobre o corpo, mas a interpretação de uma estrutura complexa de relações entre o nosso corpo e o olhar de outros sobre ele. O olhar desse outro faz referência aos saberes próprios de um momento cultural - episteme - que determinam as práticas dos sujeitos que estão imersos nessa realidade. Existem estruturas nessa realidade que são responsáveis pelo balizamento dos sujeitos com as suas práticas. Essas estruturas estão presentes nas diversas atividades realizadas no cotidiano e que, por sua vez, moldam e direcionam nosso corpo, a partir de micropoderes. O saber médico que se constitui na modernidade, com o seu discurso, é um exemplo cabal disso.

COSTA, Leandro Sousa; CAMARGO, Leonardo Nunes. Disciplina e poder: breves considerações sobre a questão do corpo na filosofia de Michel Foucault. Griot : Revista de Filosofia, Amargosa - BA, v.19, n.1, p.127-138, fevereiro, 2019. 
Sendo assim, quando dirigimos uma investigação que tem por objetivo a definição do sujeito ou a explicitação daquilo que ele é, trazemos à superfície os processos e estruturas que caracterizam uma cultura, o espaço onde o sujeito está. Ora, a filosofia foucaultiana, na nossa percepção, tem o mérito de desnaturalizar aquilo que se acredita arbitrariamente como um dado natural. A modernidade nos fez crer que o sujeito era um dado natural, universal e absoluto, todavia, o pensador de Vigiar e Punir, nos leva a perceber que o sujeito não é soberano de uma verdade, ele é, sim, objeto que pode ser conhecido por meio de divisões normativas. Isso é, na nossa percepção dos textos do filósofo, resultado da força de coação promovida pelos dispositivos disciplinadores da modernidade.

A partir das questões postas acima é possível se inquirir do seguinte modo: o que, na perspectiva do Foucault, seria esse corpo? Bem, uma impressão fortíssima deixada nos textos do filósofo é a de que o corpo é lugar, mas esse lugar - o espaço não é entendido no sentido dos físicos e sim uma instância na qual se lida com sujeitos. O corpo, por isso, sempre está aqui e se constitui como um fragmento espacial que dá condições para uma corporização, isto é, para um tornar-se sujeito. 


\section{Referências}

FONSECA, Ângela Couto Machado. Poder e corpo em Foucault: qual corpo? Fortaleza, Nomos, v.35, 2015, p.13-31.

FOUCAULT, Michel. As palavras e as coisas. São Paulo: Martins Fontes, 1981.

FOUCAULT, Michel. Ditos e escritos: estratégia, poder-saber. Tradução Vera Lucia Avelar Ribeiro. Rio de Janeiro: Forense Universitária, 2003.

FOUCAULT, Michel. O nascimento da clínica. Tradução de Roberto Machado. Rio de Janeiro: Forense Universitária, 2008.

FOUCAULT, Michel. Vigiar e punir. Tradução Raquel Ramalhete. $23^{\text {a }}$ ed. Rio de Janeiro: Vozes, 2000.

RODRIGUES, Sérgio Murilo. A relação entre o corpo e o poder em Michel Foucault. Belo Horizonte, Psicologia em Revista, v.9, n.13, jun. 2003, p. 109-124.

SILVA, Marcos Vinícius Paim da. Controle e normalização: Michel Foucault e a relação entre corpo e poder. Salvador, Domus On Line (FBB), v. 3, 2008, p. 87-98. YAZBEK, André Constantino. 10 lições sobre Foucault. Petrópolis: Vozes, 2014.

Contribuição dos autores

Leandro Sousa Costa e Leonardo Nunes Camargo contribuíram com a pesquisa, debate e redação do artigo. Ambos os autores aprovaram a versão final do texto.

Autor(a) para correspondência: Leonardo Nunes Camargo, Pontifícia Universidade Católica do Paraná - Campus Curitiba, Rua: Imaculada Conceição, 1155, Prado Velho, 80215-901, Curitiba - PR, Brasil. leonardonncamargo@gmail.com

COSTA, Leandro Sousa; CAMARGO, Leonardo Nunes. Disciplina e poder: breves considerações sobre a questão do corpo na filosofia de Michel Foucault. Griot : Revista de Filosofia, Amargosa - BA, v.19, n.1, p.127-138, fevereiro, 2019. 